\title{
La recreación del espacio natural en el interior del espacio urbano: Casa del placer honesto, de Salas Barbadillo
}

\author{
Manuel Piqueras Flores \\ Universidad de Castilla-La Mancha, España \\ manuel.piquerasflores@gmail.com \\ https://orcid.org/0000-0002-0109-1704
}

Recibido: 17 de agosto 2017

Aceptado: 3 de marzo 2018

\section{Resumen:}

El presente artículo estudia la configuración espacial del marco de Casa del placer honesto. Gracias al análisis de los elementos naturales presentes en la casa donde transcurre la acción (jardín y fuentes), y a la creación de ambientes que recrean la naturaleza a partir de la imitación, es posible concluir que en la obra esisste una búsqueda progresiva del locus amoenus dentro del locus inhospitus de la ciudad. Esta línea ascendente se quiebra abruptamente con la llegada de la enfermedad, que pone de manifiesto la imposibilidad de la utopía

Palabras clave: Marco; Ciudad; Naturaleza; Casa; Placer honesto.

\section{The recreation of natural space inside of urban space: Casa del placer honesto by Salas Barbadillo.}

\begin{abstract}
:
This paper studies the configuration of space in the frame of Casa del placer honesto. Through the analysis of natural elements present in the house where the action takes place (the garden and fountains), and the creation of environments that recreate nature by imitation, it is possible to conclude that the work introduces a progressive pursuit of locus amoenus inside of the urban locus inhospitus. This ascending line breaks down abruptly when the illness arrives, and the impossibility of utopia is discovered.
\end{abstract}

Keywords: Frame; City; Nature; House; Honest pleasure

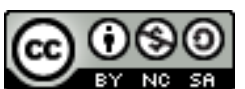

La Revista Estudios es editada por la Universidad de Costa Rica y se distribuye bajo una Licencia Creative Commons Atribución-NoComercial-Compartirlgual 3.0 Costa Rica. Para más información envíe un mensaje a revistaestudios.eeg@ucr.ac.cr. 


\section{Especial: Naturaleza amena y naturaleza agreste en las letras hispánicas}

Como es bien conocido, en el Decameron de Giovanni Boccaccio diez jóvenes florentinos de clase acomodada (siete mujeres y tres hombres) deciden abandonar Florencia para huir de la peste negra que asola la ciudad y trasladarse a una villa en las afueras. La contraposición entre el espacio urbano - símbolo de muerte y destrucción - y el espacio natural, que se presenta como el ambiente idóneo para el cultivo de la vida, la juventud, la belleza y el placer honesto, resulta claro y explícito en el propio texto:

lo giudicherei ottimamente fatto che noi, sì come noi siamo, sì come molti innanzi a noi hanno fatto e fanno, di questa terra uscissimo, e fuggendo come la morte i disonesti essempli degli altri onestamente a' nostri luoghi in contado, de' quali a ciascuna di noi è gran copia, ce ne andassimo a stare, e quivi quella esta, quella allegrezza, quello piacere che noi potessimo, senza trapassare in alcuno atto il segno della ragione, prendessimo. Quivi s'odono gli uccelletti cantare, veggionvisi verdeggiare i colli e le pianure, e i campi pieni di biande non altramenti ondeggiare che il mare, e d'alberi ben mille maniere e il cielo più apertamente, il quale, ancora che crucciato ne sia, non per ciò le sue bellezze eterne ne nega, le quali molto più belle sono a riguardare che le mura vote della nostra città; e èvvi, oltre a questo, l'aere assai più fresco, e di quelle cose che alla vita bisognano in questi tempi v'è la copia maggiore, e minore il numero delle noie. ${ }^{1}$ (Boccaccio, 1992, p. 3536)

El espacio natural tiene algo de marco utópico (Galván Álvarez, 2007) que propicia el cultivo de la literatura como forma de entretenimiento. Esta idea es

\footnotetext{
${ }^{1}$ En traducción de María Hernández: Yo estimaría muy adecuado que, en esta situación, tal como muchos antes que nosotras han hecho y hacen, saliésemos de nuestra ciudad, y huyendo como de la muerte de los deshonestos ejemplos, fuésemos a quedarnos honestamente en nuestras posesiones del campo, que todas poseemos en abundancia, y allí disfrutásemos de la fiesta, la alegría y el placer que pudiésemos, sin traspasar en acto alguno el topo de la razón. Allí se oyen cantar a los pajarillos, se ven verdear las colinas y los llanos, y los campos de mieses ondear como el mar, y una y mil especies de árboles, y el cielo más abiertamente, que, aunque esté aún enojado, no por ello nos niega sus bellezas eternas, que son mucho más bellas de contemplar que las murallas vacías de nuestra ciudad; y allí, además, el aire es mucho más fresco y mucha más abundancia de esas cosas que son necesarias para la vida en estos tiempos, y es menor el número de molestias. (Boccaccio, 2005, p. 127)
}

\section{(c) (i) (2)}

La Revista Estudios es editada por la Universidad de Costa Rica y se distribuye bajo una Licencia Creative Commons Atribución-NoComercial-Compartirlgual 3.0 Costa Rica. Para más información envíe un mensaje a revistaestudios.eeg@ucr.ac.cr. 
Especial: Naturaleza amena y naturaleza agreste en las letras hispánicas

recogida por otros autores posteriores de colecciones de novela corta, no solamente en Italia, sino también en España, cuando el género desemboca en el siglo XVII. Cervantes, que prescinde de un marco que agrupe sus Novelas ejemplares cuando intenta posicionarse como creador de la novela corta en español (Santos de la Morena, en prensa), relaciona en el prólogo los elementos de carácter natural diseñados por el hombre para favorecer el descanso (fuentes, alamedas, jardines) con el placer literario:

Sí que no siempre se está en los templos, no siempre se ocupan los oratorios; no siempre se asiste a los negocios, por calificados que sean. Horas hay de recreación, donde el afligido espíritu descanse. Para este efeto se plantan las alamedas, se buscan las fuentes, se allanan las cuestas y se cultivan con curiosidad los jardines. (Cervantes, 2013, p. 19)

Como hemos apuntado (Piqueras Flores y Santos de la Morena, 2013, p. 15-16), la argumentación del complutense es similar a la del licenciado Vidriera a la hora de defender el papel de los comediantes en la sociedad: "son necesarios en la república, como lo son las florestas, las alamedas, y las vistas de recreación, y como lo son las cosas que honestamente recrean" (Cervantes, 2013, p. 293) dirá Tomás Rodaja.

Muchas de las colecciones barrocas que contienen novelas cortas utilizan alusiones similares, especialmente a los jardines (Copello, 2010), bien en el título, bien en el marco (Colón Calderón, 2013), como por ejemplo los Cigarrales de Toledo, en los que todo el Cigarral segundo se desarrolla en torno a un jardín que funciona como laberinto de amor (Arellano, 2003; Dartai-Maranzana, 2010, Piqueras Flores, 2015a). Este hecho ha provocado incluso que intuyamos el posible género de obras no escritas, como Las semanas del jardín que anuncia Cervantes (García López, 2013, p. 20; Piqueras Flores, 2015b, pp. 119-120), aunque a veces haya provocado ciertas confusiones, como en el caso de los Días

\section{(c) (i) (2)}

La Revista Estudios es editada por la Universidad de Costa Rica y se distribuye bajo una Licencia Creative Commons Atribución-NoComercial-CompartirIgual 3.0 Costa Rica. Para más información envíe un mensaje a 
Especial: Naturaleza amena y naturaleza agreste en las letras hispánicas del jardín, texto publicado por Alonso Cano de Urrueta en 1619 y que nada tiene que ver con una colección de novela corta (Piqueras Flores, 2016a, p. 85).

Dentro de las colecciones de inspiración boccaccesca que se escribieron en España en las primeras décadas del siglo XVII, Casa del placer honesto ocupa un papel destacado. Esta obra de Alonso de Salas Barbadillo se articula en torno a un marco que inserta seis novelas cortas, cuatro piezas teatrales breves y varias poesías. Es por ello la primera colección en introducir, además de novelas cortas, otro tipo de material literario a partir de un marco ${ }^{2}$, apenas unos años antes de que lo hiciera Tirso de Molina en sus Cigarrales de Toledo. La influencia del modelo del Decameron en la configuración de la cornice de Casa del placer honesto fue señalada ya por Caroline Bourland (1905, p. 194), Menéndez Pelayo (2008, p. 27) y Edwin Place, este último de manera algo más extensa en la introducción a su edición de la obra (1927, pp. 317-320); de manera más reciente han hecho alusión a ella Antonio Rey Hazas (1986: 30) y Enrique García Santo-Tomás (2008: 95).

La narración inicial, que devendrá en marco, presenta a cuatro jóvenes andaluces conversando en las orillas del Tormes. Se trata de acaudalados estudiantes de la Universidad de Salamanca que deciden dejar los estudios y mudarse a la corte para fundar una "casa del placer honesto":

Tormes ilustre por las armas y blasones de los antiguos caballeros ciudadanos de Salamanca, y no menos insigne por las letras de tanto felices ingenios, que han sido admiración y gloria de la Europa: una tarde de abril amenísima entonces en sus alegres campos albergó en ellos a cuatro caballeros andaluces primogénitos de sus casas, cuyos nombres eran don Fernando, dos Próspero, don García y don Diego, que estudiaban más por ambición de sus padres que por necesidad de la facultad de los derechos, a quien el claro río oyó discurrir de este modo [...]:

-Gocemos nosotros como aquellos que nacimos con aventajada estrella de la dulce libertad, por ningún precio bien vendida: vámonos a

\footnotetext{
${ }^{2}$ Para describir esta situación, que va más allá de la novela corta, hemos articulado la terminología "colección de metaficciones" (Piqueras Flores, 2016b; 2018).

La Revista Estudios es editada por la Universidad de Costa Rica y se distribuye bajo una Licencia Creative Commons Atribución-NoComercial-Compartirlgual 3.0 Costa Rica. Para más información envíe un mensaje a revistaestudios.eeg@ucr.ac.cr.
} 
Especial: Naturaleza amena y naturaleza agreste en las letras hispánicas

la Corte y vivamos allí con los alimentos y socorros que es fuerza que nos envíen nuestros padres; en apacible y no escandaloso deleite fundaremos una casa que intitularemos del placer honesto. (Salas Barbadillo, 1620, ff. 1r-2r) ${ }^{3}$.

El comienzo tiene una ambientación natural idílica tanto porque se sitúa a orillas del Tormes - recordemos la influencia de los ríos en la construcción del espacio de la novela pastoril renacentista (Piqueras Flores, 2017, pp. 198-199)_ como por las condiciones climatológicas: "una tarde de abril amenísima" con "alegres campos". Lo curioso de Casa del placer honesto es que, sin embargo, no será este entorno sobre el que se construya la cornice, sino que habrá un desplazamiento hacia el interior de lo urbano. Para fundar su casa del placer honesto, los cuatro jóvenes no solo no eligen un ambiente bucólico, sino que se alejan de él para internarse en el mundo diametralmente opuesto. El establecimiento de la corte la Monarquía Hispánica de manera permanente en Madrid había provocado que la urbe creciera de manera considerable a lo largo de las últimas décadas del siglo XVI y de las primeras del siglo XVII. Pronto veremos que el proyecto de constituir una casa del placer honesto en el corazón de la ciudad tiene que ver con la idea de reproducir lo positivo del entorno natural:

- Si nosotros ocupamos este campo, ¿qué dejamos libre a las acciones de los que nacieron sin ricas posesiones, herencias de sus antepasados como las nuestras? Sigan ellos el cautiverio de sus miserables hados, y gocemos nosotros como aquellos que nacimos como aventajada estrella de la dulce libertad. (f. 2 r)

Para don Diego, uno de los cuatro estudiantes, que es también el que propone el nuevo proyecto de vida de los jóvenes, el entorno natural es válido para el campesinado, porque en él pueden realizar su vida sin dificultades; sin embargo, en Madrid el hombre cortesano tiene la capacidad de desarrollar todas

${ }^{3}$ Citamos por la edición princeps modernizando la ortografía.

\section{(c) (†) (-)}

La Revista Estudios es editada por la Universidad de Costa Rica y se distribuye bajo una Licencia Creative Commons Atribución-NoComercial-Compartirlgual 3.0 Costa Rica. Para más información envíe un mensaje a revistaestudios.eeg@ucr.ac.cr. 
Especial: Naturaleza amena y naturaleza agreste en las letras hispánicas

sus facultades. Como hemos apuntado en un trabajo anterior, "la corte no se desarrolla como el marco social idóneo, sino que es un ejercicio obligatorio para los hombres afortunados por su estado, es decir, para aquellos que por su nobleza tienen el sustento garantizado" (Piqueras Flores, 2018). Por ello, los fundadores de la casa del placer honesto replicarán los espacios naturales en la ciudad:

Alquilaron una casa de comunidad junto al Prado, donde había servicio de cuarto bajo y alto; tenía más adentro un jardín hermoso acompañado de fuentes, sobre el cual discurría una galería grande, que ocuparon todos su libros, formando una librería varia y curiosa de todas las ciencias y facultades (f. 2v).

El lugar elegido para establecerse en Madrid es el Prado, el límite de la ciudad hacia el oeste, donde se situaban las huertas de recreo, y, donde ciertamente, el contacto con la naturaleza sería mayor. Según García Santo-Tomás (2008: 96), el Prado era además "el mejor barrio de Madrid" en la época. La presencia de un jardín acompañado de fuentes es una muestra de la construcción de espacios con elementos naturales no ya dentro de la ciudad, sino también de las casas mismas, y recuerda a los jardines, alamedas y fuentes a los que hacía referencia Cervantes en el prólogo de las Ejemplares. A partir de este momento toda la acción del marco se desarrolla en el interior de la casa, sin pisar las calles de Madrid. Como indica García Santo-Tomás:

En una ciudad notoriamente sucia, ruidosa, y llena de peligros, el espacio doméstico - siguiendo acaso el paralelo de la peste medieval que hizo refugiarse a los contertulios florentinos del Decamerón-es el oasis de paz y orden, alimentándose del prestigio de la Corte pero sin los inconvenientes de la ciudad. (2008, p. 96).

Una vez instalados, los cuatro miembros fundan oficialmente la casa del placer honesto, una "comunidad" (f. 4r) regida por unas "constituciones" (f. 5r) que se desarrollan notablemente. Entre ellas destaca la ausencia de mujeres a los 
Especial: Naturaleza amena y naturaleza agreste en las letras hispánicas festejos organizados. Ese mismo domingo organizan una "primera ostentacion" pública a la que invitan a otros cortesanos. Para ello, acondicionan una de las salas a modo de teatro, cercándola con gradas a los costados y dejando un escenario en el centro para las representaciones dramáticas, y una cátedra y un trono a sendos lados de la entrada. Adornan el suelo, "por ser ya verano, de frescas rosas y floridas yerbas". Además, Salas Barbadillo describe las vistas al jardín con fuentes, que, suponemos, es el mismo descrito anteriormente:

Las ventanas correspondían a un jardín, y enfrente dellas se veían dos fuentes de maravilloso artificio y no pequeño golpe de agua. Guardada [la sala] pues de todas partes de los rayos del sol, y alentada del fresco que de las fuentes salía, recogiendo de paso el aliento de unos jazmines estaba su sitio ameno y apacible. (f. 6v).

Al igual que al describir la orilla del Tormes, Salas habla de un lugar "ameno", donde, ahora sí, se va a cultivar la literatura en todas sus formas. La presencia de los jazmines puede tener que ver quizá, para Isabel Colón, con el Decameron (2013: 140), pero, en cualquier caso, tanto estos como el suelo cubierto de flores y hierbas suponen una naturalización de la casa, que se presenta propicia para la recreación de los sentidos, no solo de la vista y del oído, sino también del olfato.

Una vez que se admiten a dos nuevos miembros en la casa, los festejos se realizan con una periodicidad mensual, siempre coincidiendo con una celebración religiosa señalada. Uno de los caballeros dirige la organización y encarga al resto una tarea determinada, no solo relacionada con la literatura (lectura de una novela, representación de una obra dramática o recitación de un poema) sino también con la decoración de la sala, a la que Salas Barbadillo le da un papel notorio. En la segunda fiesta, celebrada el día de Santiago, la sala recrea de nuevo un ambiente natural: "No hubo más tapicería que haber repartido por la pieza desde el techo hasta el lugar donde se sentaban, puestos por tal orden entre

\section{(c) (i) (2)}

La Revista Estudios es editada por la Universidad de Costa Rica y se distribuye bajo una Licencia Creative Commons Atribución-NoComercial-CompartirIgual 3.0 Costa Rica. Para más información envíe un mensaje a 
Especial: Naturaleza amena y naturaleza agreste en las letras hispánicas

unas hojas de árboles que vestían las paredes, que parecieron fruto dellas mismas" (f. 90r).

Más allá de las representaciones teatrales ("diálogos" y "comedias domésticas" según la terminología que les da Salas Barbadillo a lo largo de Casa del placer honesto), hay otros aspectos dramáticos que tienen que ver con la presencia de poemas musicados. En la tercera fiesta, celebrada en agosto, la recitación lírica adquiere además elementos escenográficos de notable complejidad, como la existencia de una fuente de la que sale un joven vestido de ninfa:

Don Juan [...] había plantado una fuente en medio de la sala, que era un valentísimo peñasco que sudaba por todas partes corrientes de agua clarísima. Este, luego que la imagen del santo tuvo su asiento y enmudecieron los instrumentos que la festejaban, se dividió en dos partes, y en medio dél se descubrió sentado en una silla un mancebo de pocos años; que vestido de una tunicela y puesta una cabellera en la cabeza, pareciéndose ninfa de aquella fuente, cantó con tan sonoros acentos que hizo que se tuviese por verdad [...]. Desde allí con suma velocidad fue arrebatado, y pasó del lugar que ocupaba entre el peñasco de la fuente al teatro. (f. 121r-v)

Dejando a un lado los problemas de verosimilitud que conlleva la existencia de una fuente de estas características, de nuevo vemos la intención de recrear el lugar ameno de tipo natural, asociado no solo con la vegetación anterior, sino también con el "agua clarísima" de la fuente artificial.

El mayor nivel de complejidad de la decoración se alcanza en la cuarta y última fiesta, y de nuevo el artificio tiene que ver con una imitación de lo natural: no ya de los elementos vegetales ni manantiales, sino del mismo cielo:

La imagen del santo era también de plata sobredorada, y todas cuantas cosas ocuparon el altar fueron de lo mesmo: el techo, todo lleno de estrellas de vidrio deste de que se hacen los diamantes fingidos; y en medio la luna, formada de la mismas materia, brillaba con tantas luces y 
Especial: Naturaleza amena y naturaleza agreste en las letras hispánicas resplandores que era apacible imitación de la verdad (f. 153r)

De nuevo está presente no solo la recreación visual sino también la olfativa: "la pieza estaba toda rociada con agua de olor, y repartidas por sus puestos algunas vasijas que la tenían en cantidad para los que se quisiesen refrescar y regalarse con ella" (f. 153r).

Como vemos, hay un progresivo aumento de la complejidad y la dificultad de imitación de la naturaleza, que es posible únicamente gracias al estatus socioeconómico de los miembros de la casa. Existe en este sentido todo un despliegue de medios y facultades para crear un oasis en medio de la ciudad de Madrid, que intenta liberar a los cortesanos de la vida que está más allá, tras los muros de la casa. Sin embargo, esta experiencia de recreación que asciende gradualmente se interrumpe bruscamente al final de la obra. Los académicos deciden disolver la comunidad cuando don García, uno de ellos, contrae "tabardillo", es decir, tifus. Como indica Noelia Cirnigliaro:

No sin cierta ironía trágica, la aflicción más grande para García y la comunidad llega de la mano de una enfermedad cuyo remedio no puede comprar el dinero, el lujo o el ingenio de los nobles amigos. Una de las pocas máximas del narrador, engastada en el tópico barroco de la brevedad de la vida, subraya la paradoja intrínseca de placer: "que con tanta brevedad tienen fin en este mundo aún los placeres que son más honestos y lícitos". (Cirnigliaro, 2015, p. 163)

El final parece inclinar la balanza hacia el desengaño, hacia la imposibilidad de construir la utopía literaria y artística dentro de la nueva Babilonia de la corte. De la misma manera, los decorados son cada vez más complejos en la imitación de la naturaleza, pero a diferencia de esta, acaban resultando tan efímeros como el proyecto de los miembros de la Casa del placer honesto.

\section{(c) (i) (2)}

La Revista Estudios es editada por la Universidad de Costa Rica y se distribuye bajo una Licencia Creative Commons Atribución-NoComercial-CompartirIgual 3.0 Costa Rica. Para más información envíe un mensaje a 
Especial: Naturaleza amena y naturaleza agreste en las letras hispánicas

\section{BIBLIOGRAFÍA}

Arellano, Ignacio (2003). "La cultura simbólica y alegórica en Los cigarrales de Toledo de Tirso de Molina", Versants, No. 43, pp. 5-23.

Boccaccio, Giovanni (1992). Decameron, ed. Vittorio Branca. Torino: Einaudi.

Boccaccio, Giovanni (2005). Decameron, ed. y trad. María Hernández. Madrid: Cátedra.

Bourland, Caroline B. (1905). Boccaccio and the 'Decameron' in Castillian and Catalan Literature. En Revue Hispanique, № 12, pp. 1-231.

Cervantes Saavedra, Miguel de (2013). Novelas ejemplares, ed. Jorge García López. Madrid: Galaxia Gutenberg-Círculo de Lectores.

Cirnigliaro, Noelia S. (2015). Domus. Ficción y mundo doméstico en el barroco español. London: Tamesis.

Colón Calderón, Isabel (2013), "Narrar en corro y narrar desde un sitio especial: algunas consideraciones sobre el marco boccacciano en la novela corta española del XVII". En Isabel Colón Calderón et. al. (eds.). Los viajes de Pampinea: 'novella' y novela española en los Siglos de Oro. Madrid: Sial, pp. 137-149.

Copello, Fernando (2010). "Marcos narrativos ajardinados en las colecciones de novelas cortas españolas del siglo XVII". En Pierre Civil y Françoise Crémoux, Actas del XVI Congreso Internacional de la Asociación Internacional de Hispanistas. Madrid/Frankfurt: Iberoamericana/Vervuert, v. 2, pp. 109-116.

Dartai-Maranzana, Nathalie (2010). "Bois d'Amour, jardins et château dans les Cigarrales de Toledo". En Bulletin Hispanique, No. 112, I, pp. 131-147.

Galván Álvarez, Enrique (2007). "El espacio utópico y las mujeres en el Decamerón". En Clepsidra, No. 6, pp. 73-89.

García López, Jorge (2013). “Introducción”. En Miguel de Cervantes. Novelas ejemplares. Madrid: Galaxia Gutenberg-Círculo de Lectores.

\section{(c) (i) (2)}

La Revista Estudios es editada por la Universidad de Costa Rica y se distribuye bajo una Licencia Creative Commons Atribución-NoComercial-CompartirIgual 3.0 Costa Rica. Para más información envíe un mensaje a 
Especial: Naturaleza amena y naturaleza agreste en las letras hispánicas

García Santo-Tomás, Enrique (2008). Modernidad bajo sospecha. Salas Barbadillo y la cultura material del siglo XVII. Madrid: CSIC.

Menéndez Pelayo, Marcelino (2008). Orígenes de la novela. Madrid: Gredos.

Place, Edwin B. (1927). «Edición, introducción y notas» de Alonso J. de Salas Barbadillo. Casa del plazer honesto. En University of Colorado Studies, № 15.4. Boulder (Colorado): University of Colorado.

Piqueras Flores, (2015a). "De Italia a España: la búsqueda y la creación del marco en Los cigarrales de Toledo, de Tirso de Molina". En Guillermo Carrascón et al. (eds.). I novellieri italiani e la loro presenza nella cultura europea: rizomi e palinsesti rinascimentali. Torino: Accademia University Press, pp. 556568.

Piqueras Flores, Manuel (2015b). "Elementos de la novela corta en la segunda parte del Quijote". En Anuario de Estudios Cervantinos, No. 11, pp. 113124.

Piqueras Flores, Manuel (2016a). "El nacimiento de las colecciones de novela corta en español". En Mechthild Albert (et al.) (eds.). Nuevos enfoques sobre la novela corta barroca. Bern: Peter Lang, pp. 77-91.

Piqueras Flores, Manuel (2016b). "Alonso J. de Salas Barbadillo y el nacimiento de las colecciones de metaficciones áureas". Castilla. Estudios de Literatura. No. 7 , pp. 794-811.

Piqueras flores, Manuel (2017). "De la literatura a la metaliteratura: una aproximación al espacio pastoril en los Siglos de Oro". En Raquel Crespo Vila y Sheila Pastor (eds.). Dimensiones: el espacio y sus significados en la literatura hispánica. Madrid: Biblioteca Nueva, pp. 195-204.

Piqueras Flores, Manuel (2018) (en prensa). La literatura en el abismo: Salas Barbadillo y las colecciones de metaficciones. Vigo: Academia Editorial del Hispanismo.

Piqueras Flores, Manuel y Santos de la Morena, Blanca (2013). "Cervantes y el teatro breve más allá de la representación: un entremés intranovelesco en La ilustre fregona". En Anagnórisis. Revista de investigación teatral, No. 7, pp. 6-17.

\section{(c) 100}

La Revista Estudios es editada por la Universidad de Costa Rica y se distribuye bajo una Licencia Creative Commons Atribución-NoComercial-CompartirIgual 3.0 Costa Rica. Para más información envíe un mensaje a revistaestudios.eeg@ucr.ac.cr. 
ISSN 1659-3316

Diciembre 2018

Especial: Naturaleza amena y naturaleza agreste en las letras hispánicas

Rey Hazas, Antonio (ed.) (1986). Picaresca femenina. La hija de Celestina. La niña de los embustes. Teresa de Manzanares. Madrid: Plaza y Janés.

Salas Barbadillo, Alonso de (1620). Casa del placer honesto. Madrid: Viuda de Cosme Delgado.

Santos de la Morena, Blanca (en prensa). "De Boccaccio a Cervantes: las Novelas ejemplares, propuesta de colección de novela corta a la española". En Les métamorphoses de Boccace. Paris: Garnier.

La Revista Estudios es editada por la Universidad de Costa Rica y se distribuye bajo una Licencia Creative Commons Atribución-NoComercial-CompartirIgual 3.0 Costa Rica. Para más información envíe un mensaje a revistaestudios.eeg@ucr.ac.cr. 